\title{
NOTAS LÉXICAS A SAFO Y ALCEO
}

This paper comments on several terms from the fragments of Sappho and Alcaeus, addenda et corrigenda to the main dictionaries of ancient Greek.

Dentro de la extraordinaria riqueza léxica de los poemas lesbios hay que contar con un número bastante llamativo de términos no suficientemente explicados desde el punto de vista semántico, en ocasiones también formal. Ello es consecuencia directa de dos factores principales: en primer lugar el estado fragmentario o corrupto de la mayor parte del texto y los graves problemas críticos que acarrean tanto la transmisión papirácea como la indirecta. En segundo lugar la complejidad lingüística y léxica de dicho texto, donde el vocabulario tradicional, reelaborado y adaptado de diversas formas, se mezcla con un amplio volumen de novedades en términos, sentidos y usos literarios, y con un elemento dialectal difícil de delimitar.

Este artículo agrupa una serie de notas léxicas de distinto tipo, a modo de addenda et corrigenda a los principales diccionarios generales, el de Liddell-Scott-Jones ( $L S J$ ) y el Diccionario Griego-Español, vols. IIII $(D G E)^{\prime}$.

En primer lugar presento algunas interpretaciones personales de palabras cuyo significado es discutido, interpretaciones que resumo cuando han sido publicadas en otro lugar, o que argumento en detalle si son nuevas. Otras veces simplemente aporto argumentos a favor de interpretaciones ajenas, bien sean antiguas o más novedosas.

Para obtener un panorama más completo añado aquellos términos que deben ser corregidos en los diccionarios, en algún caso porque se

$'$ H. G. Liddell, R. Scott, H. S. Jones, R. MacKenzie: Greek-English Lexicon, Oxford $1940_{9}$; E. A. Barber, P. Maas, M. Scheller, M. L. West, Greek-English Lexicon. A Supplement, Oxford 1968; AA.VV., Diccionario Griego-Español I-III, Madrid 1980-1991.

${ }^{2}$ E. M. Voigt, Sappho und Alkaios. Fragmenta, Amsterdam 1971. 
ha llegado recientemente, al menos a nuestro modo de ver, a una solución satisfactoria. Sin querer enumerar todos los términos significativos que están ausentes de los diccionarios, para lo cual bastaría con leer el indice de palabras de la edición de Voigt ${ }^{2}$, añado algunos de ellos que presentan una problemática interesante o un significado excepcional digno de ser analizado y resaltado ${ }^{3}$. Finalmente aparecen una serie de palabras cuya presencia en los textos lesbios ha quedado demostrada con posterioridad a la edición de Voigt.

áyáoupтоৎ 'muy arrastrado', 'tirado', 'sucio', 'bajo', 'obsceno', Alc. $429^{7}$.

Diógenes Laercio I 81 nos testimonia varios insultos que Alceo aplicó al tirano Pítaco, entre los que figura este compuesto formado a partir de $\sigma u ́ \rho \omega$ 'arrastrar', 'tirar'. El mismo autor explica el adjetivo como

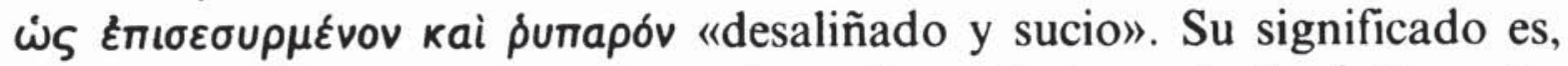
por tanto, el que exponemos en el encabezamiento o similar ${ }^{4}$. Con ello coincide la glosa de Zonaras áyáouptos $\delta$ ákáӨapтos. Se trata sin duda de una creación alcaica que parodia adjetivos típicamente épicos como

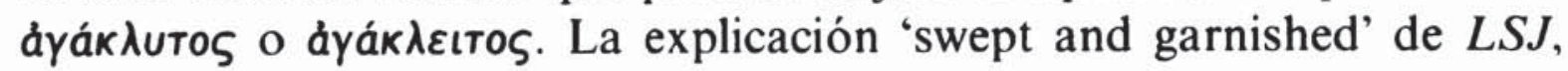
seguida por el $D G E$ 'muy peripuesto', debe ser corregida.

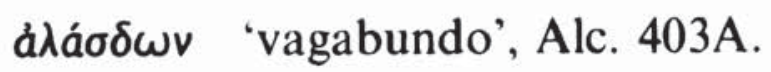

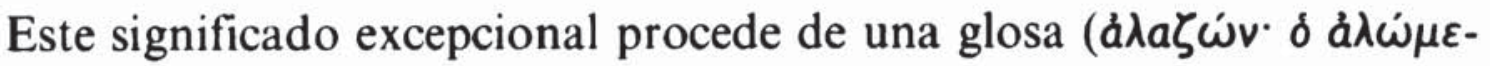

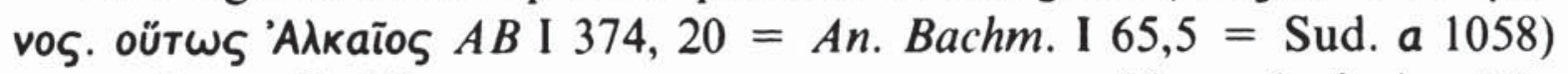
que se ha atribuido tanto a nuestro autor como a Alceo el cómico ( Fr. 37 Kassel-Austin), opción por la que se inclina el $D G E$. Si bien no sería de extrañar que este término apareciese en la obra del lírico, en cualquier caso la explicación queda incompleta si no se explica que el sentido 'vagabundo' surge simplemente de un juego de palabras con el verbo à̉áoual, que quizá aparecía en el mismo pasaje.

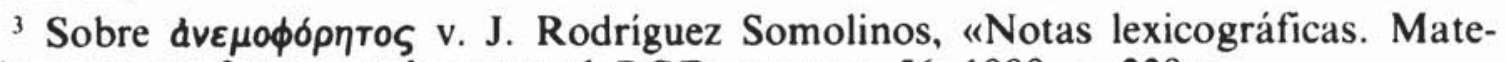
riales para un futuro suplemento al $D G E$ ». EMERITA 56, 1988, p. 239 s.

${ }^{4}$ Cf. M. Davies, "Conventional topics of invective in Alcaeus", Prometheus 11, 1985, p. 31 ss., A. Romé, "L'uso degli epiteti in Saffo e Alceo con riferimento alla tradizione epico-rapsodica», $S C O$ 14, 1965, p. 210 ss.

5 "Un commentario papiraceo ad Alceo e il fr. 130B Voigt». Aevum(ant) 2, 1989, p. 215 ss. y "A proposito di Alc. fr. 130B Voigt», QUCC 41, 1992, p. 23 ss. Para las propuestas de lectura anteriores a la aparición del POxy. $3711 \mathrm{v}$. H. Rodríguez Somolinos, Estudios sobre el léxico de Safo y Alceo, Madrid 1992, p. 275 ss. 


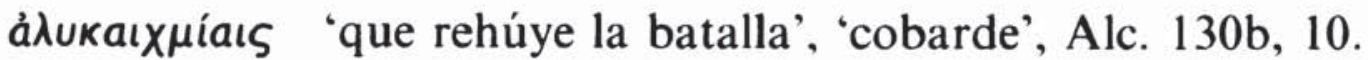

En 1989 A. Porro propuso leer este adjetivo, compuesto del tema

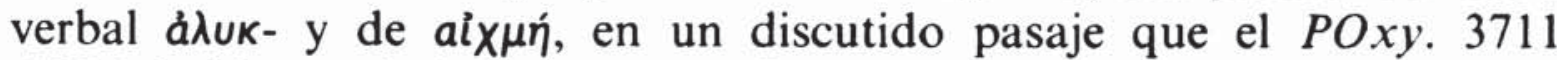
(1986) había ayudado a completar ${ }^{5}$. Si bien la interpretación general de dicha autora dejaba algunos puntos sin explicar, creo haber ayudado a

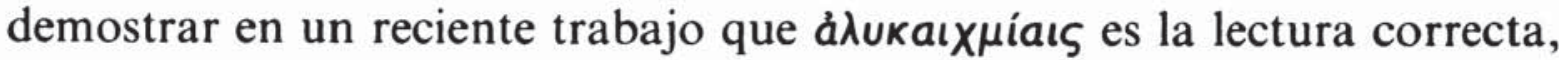
por lo que deberá figurar desde ahora en léxicos y diccionarios ${ }^{6}$.

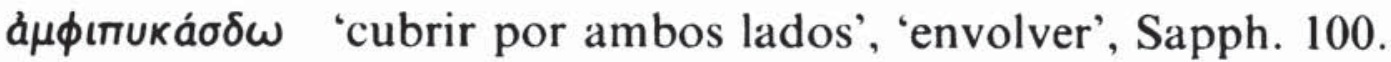

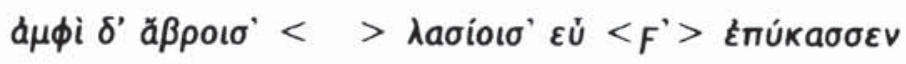

Frente a los que veían en á $\mu \phi i$ una preposición, la presencia en este fragmento del compuesto á $\mu \phi ı n u k a ́ \sigma \delta \omega$, en tmesis ${ }^{7}$, se ha visto confirmada recientemente gracias a dos nuevos testimonios. DGE II (1986)

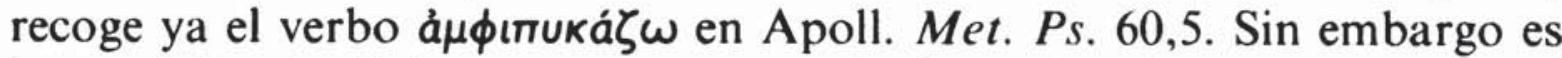
la aparición de dicho compuesto con el mismo significado en Lyr. Eleg. Adesp. en POxy. 3723, 3, probablemente de época helenística ${ }^{8}$, lo que acaba de demostrar que Safo constituye e! primer testimonio de esta

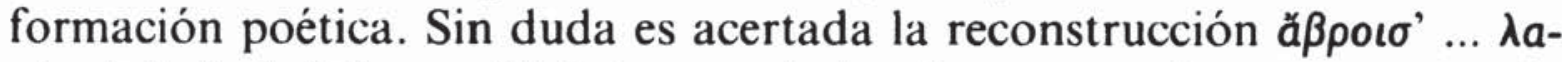
oíoı' de Lobel-Page y Voigt como dativo instrumental: «con mantos de suave pelo (lo) envolvió bien"? .

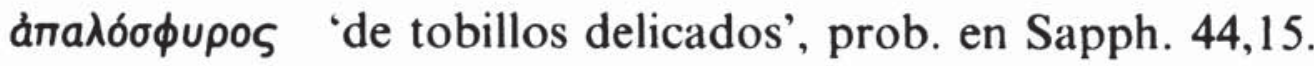

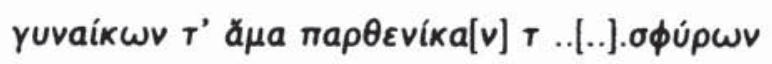

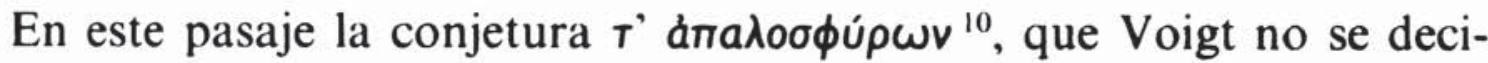
de a aceptar en el texto, resulta prácticamente segura. Desde el punto de vista paleográfico es la más adecuada ", pero además encuentra apo-

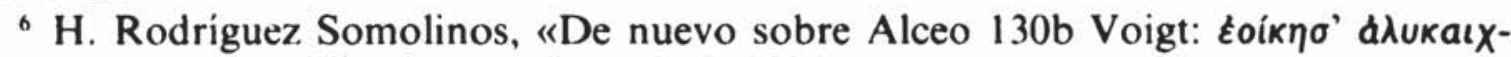

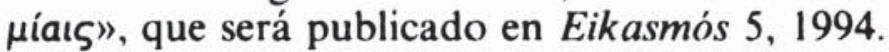

${ }^{7}$ Recurso no extraño a los poetas lesbios, vid. por ej. Sapph. 168B,3; 42,2; 63,4; 121,1 , etc.

${ }^{8} \mathrm{Cf}$. el comentario ad loc. de Parsons y, del mismo autor, "Eine neugefundene Liebeselegie», $M H 45,1988$, p. 65 ss., que ignora el pasaje sáfico y el de Apolinar.

9 Vid. ap. crít. de Voigt.

${ }_{10}$ Propuesta simultáneamente por R. Pfeiffer en Gnomon 2, 1926, p. 315 y G. M. Bolling, Lang. 1926, p. 139, n. 1. Es decididamente aceptada por C. M. Bowra, Greek Lyric Poetry, Oxford $1961_{2}$, p. 447, por M. Treu, Sappho. Lieder, Munich 1944, p. 52 y por B. Marzullo, Studi di Poesia Eolica, Florencia 1958, p. 161 ss.

$"$ Cf. ap. crit. de Voigt. Marzullo, loc. cit., argumenta acertadamente, ante la objeción de Lobel de que la lectura excede el espacio disponible en el papiro, que el 
yo en una serie de compuestos épicos similares, todos ellos aplicados a diosas o mujeres ${ }^{12}$. El adjetivo dnaגós suele aplicarse en poesía arcaica a partes del cuerpo de la mujer como el cuello o la piel, pero también frecuentemente a los pies ${ }^{13}$. Todo ello hace muy probable la existencia de este compuesto, aunque sea hapax.

ßрákєa 'harapos', Sapph. 57,3.

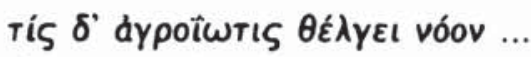

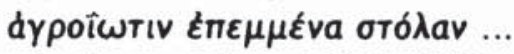

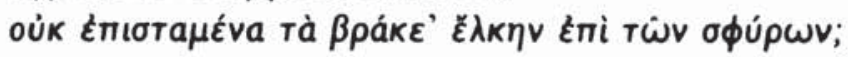

Este fragmento de Safo es especialmente discutido en primer lugar por la posibilidad de que el verso 2 esté corrupto o sea simplemente fal-

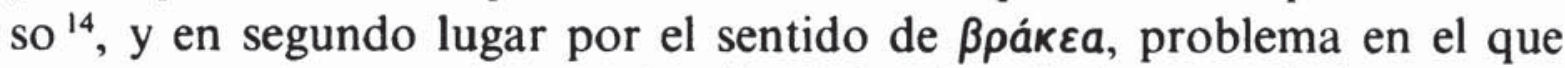
vamos a centrarnos. En apariencia el término designa aquí cierta prenda de vestir, como confirman en principio Theoc. XXVIII 11 ola yúval-

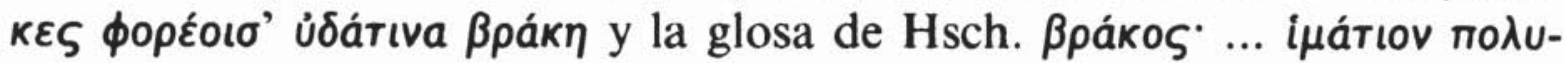

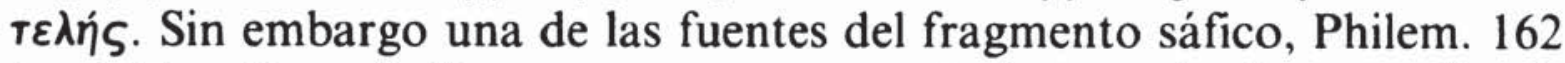
(p. 107 s. Osann) dice expresamente que ßpákos es la forma eolia de ṕákos ${ }^{15}$.

Este término pákoৎ aparece desde Homero, en singular y plural, con el significado de 'harapo', 'jirón', con una amplia familia lexical que expresa la misma noción. Por otro lado hay en Hesiquio ciertas glosas con $\beta \rho$ - que denominan instrumentos, glosas relacionadas con el ámbito

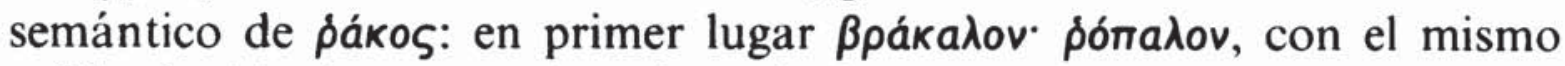

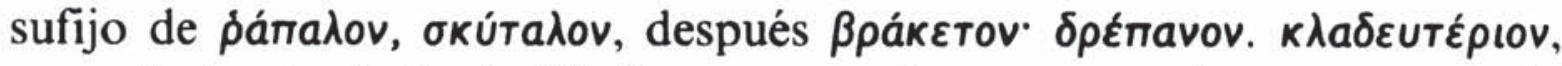

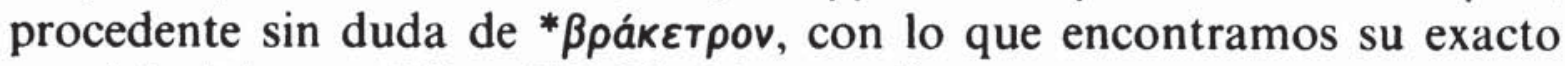
paralelo ático en Pólux VII 25: páketpov ${ }^{16}$.

ancho de las letras en dicho papiro es sumamente irregular. Otras dos propuestas,

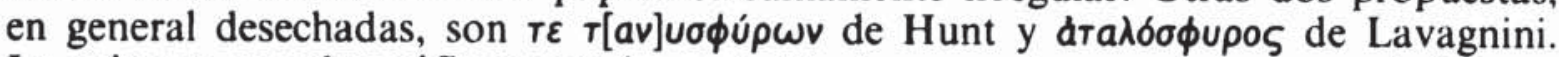
La primera es paleográficamente inaceptable. La segunda es muy poco probable, ya que el adjetivo dтaגós suele referirse en poesía arcaica a personas, y el único compuesto existente es áaגá $\rho \omega \nu$ (II. VI 400), como vemos no referido a ninguna parte

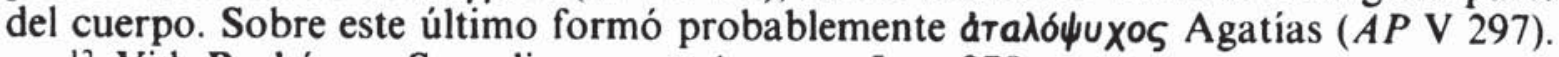

12 Vid. Rodríguez Somolinos, op. cit. en n. 5, p. 278.

13 Cf. M. Treu, Von Homer zu Lyrik, Munich $1968_{2}$, p. 178 ss. Más paralelos se pueden ver en Marzullo, loc. cit.

${ }^{14}$ Cf. Rodriguez Somolinos, op. cit. en n. 5, p. 319 y nn. 5, 6. Vid. especialmente V. Di Benedetto, "Contributi al testo di Sappho", RFIC 110, 1982, p. 13 ss.

is $\mathrm{Si}$ bien este testimonio parece proceder de una falsificación; cf. M. L. West en CR 33, 1983, p. 309.

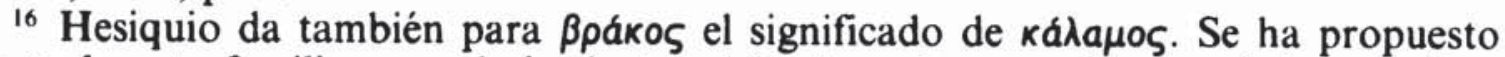
que toda esta familia procedería dentro del griego de un radical verbal de aoristo medio-pasivo * paкعĩv. La hipótesis más extendida sobre su posible etimología in- 


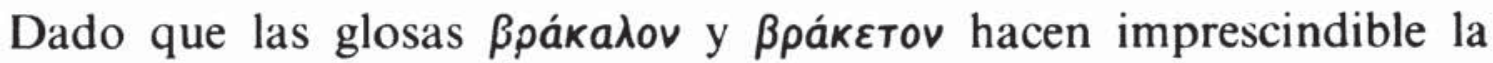
existencia de digamma también en ṕákos, es la diferencia de significado entre pákos y ßpákos, palabras formalmente idénticas salvando la característica dialectal - o grafia - lesbia ${ }^{17} \beta \rho-<F \rho$-, lo que ha llevado a suponer para ambos términos un origen etimológico independiente, idea que los diccionarios etimológicos suelen aceptar. Sin embargo, los escasos intentos de explicar cuál sería en tal caso la procedencia de $\beta \rho a ́-$ koS resultan poco satisfactorios, y conducen inevitablemente a pensar en un mismo origen ${ }^{18}$.

Es sin duda más sencillo pensar que se trata de la misma palabra y que tiene el mismo significado ${ }^{19}$. Es evidente que Safo utiliza el término irónica y despectivamente, pues es una áypoîwtıs 'palurda', 'rústica'

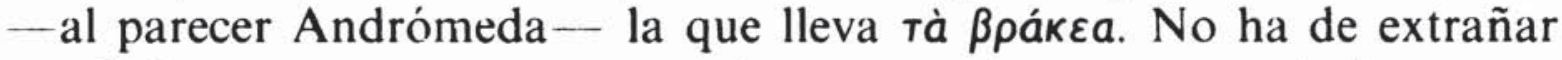
que Safo, que se muestra en ocasiones muy dura con sus rivales, acuse a la rústica rival de no saber arrastrar sus harapos sobre los tobillos. Dos detalles apoyan esta idea: en primer lugar si ßрákos denominara un vestido en el fragmento sáfico, esperaríamos la utilización del singular, como en la glosa de Hesiquio. El uso del plural aparece apuntar más al sentido 'harapos', y lo contrario resultaria sumamente extraño. En segundo lugar se nos ha dicho en el verso anterior que lo que lleva la vituperada joven es una $\sigma \tau o ́ \lambda a$, por lo que no parece apropiado en principio denominar tal prenda de otro modo en el verso siguiente.

En este caso el testimonio de Teócrito ha de proceder de una mala interpretación de Safo en época alejandrina. De esta interpretación posterior parte sin duda también la glosa de Hesiquio que, por aparecer enunciada en singular, ha sido quizá tomada de una tercera fuente que desconocemos.

doeuropea, que lo relaciona con antiguo indio vrśáti, antiguo eslavo vraska, no es del todo definitiva. Vid. P. Chantraine, Dictionnaire Etymologique de la Langue Grecque. Histoire des Mots, Paris 1983, H. Frisk, Griechisches Etymologisches Wörterbuch, Heidelberg 1954 ss., E. Boisaq, Dictionnaire Etymologique de la Langue Grecque, Heidelberg $1950_{4}$, etc. s.u. pákos.

${ }_{17}$ Vid. últimamente J. T. Hooker, The Language and Text of the Leshian Poets, Innsbruck 1977, p. 27 ss.

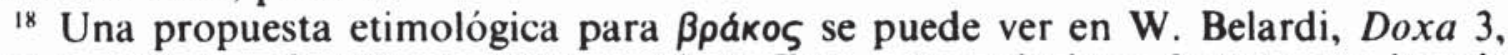
1950, p. 199 ss., cf. Maia 3, 1950, p. 59 ss. Este autor relaciona ßpákos con la raíz indoeuropea * $m(e) r k$ - 'brillar'.

${ }_{19}$ Como defienden entre otros E. Degani-G. Burzacchini, Lirici Greci, Florencia $1978_{2}$, p. 156, n. 3 y las traducciones de D. Page, Sappho and Alcaeus, Oxford 1959, p. 133, y D. A. Campbell, Greek Lyric I, Cambridge 1982, p. 101. 
Siomrpov 'mirilla', Alc. 333.

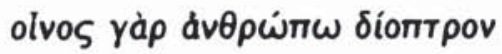

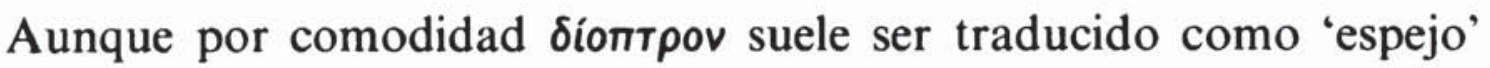
refleja un concepto muy distinto al de кáтоптроv, término documentado por primera vez en Esquilo ( $A$. 839, $F r$. 393). Como bien dice Gentili ${ }^{20}$, Alceo acude a una metáfora más expresiva, considerando el vino como un instrumento que sirve para mirar el interior del alma humana. Esta idea es la que recoge la definición de $L S J$ 'means for seeing through'. Sin embargo el poeta no puede estar mencionando ningún instrumento determinado, de muy dudosa existencia en su época. Parece acertado interpretarlo ${ }^{21}$, en cambio, como una especie de 'mirilla' o 'agujero' a través del cual, figuradamente, se podría observar el alma. La palabra podría ser de uso corriente en la lengua de Alceo, o bien ser una crea-

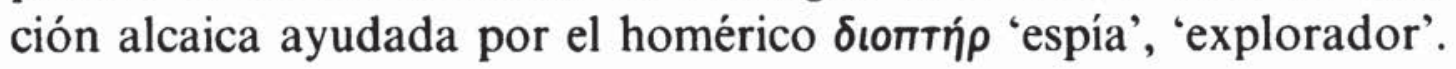

$\delta ı \omega ́ \xi ı \varsigma$ 'que puede o merece ser acusado', Alc. 358,3.

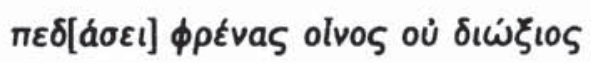

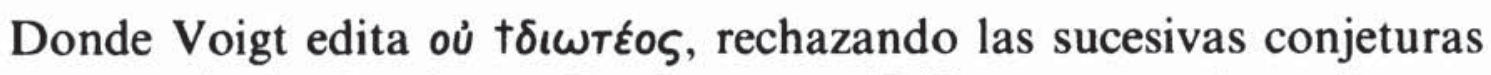
propuestas desde Bergk, ya Vogliano en 1948, tras examinar directamente el papiro de Demetrio Lacón que transmite el fragmento, leyó este adjetivo hapax $\delta \iota \omega \xi \iota^{\prime} \varsigma^{22}$. Siguiendo el comentario de Demetrio Lacón su significado ha de ser pasivo, probablemente en el sentido legal

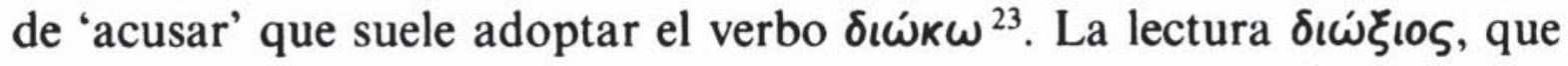
sólo había sido plenamente aceptada en la edición de Treu ${ }^{24}$, se ha revelado como correcta en la nueva lectura y edición del papiro hecha por C. Romeo ${ }^{25}$.

${ }^{20}$ En G. Perrotta-B. Gentili, Polinnia. Poesia greca arcaica, Mesina-Florencia $1965_{2}$, p. 209.

${ }^{21}$ Como hace Page, op. cit., p. 312, cf. Degani-Burzacchini, op. cit., p. 228, n. 1.

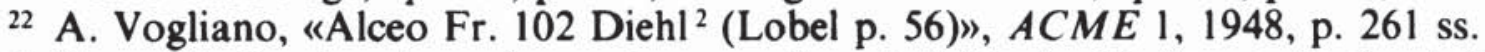

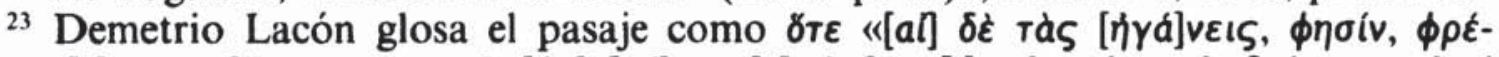

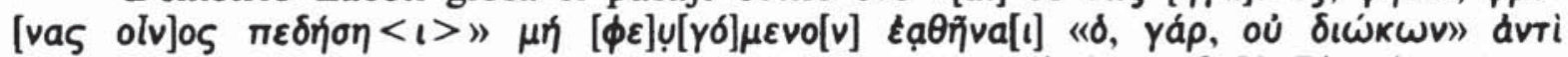

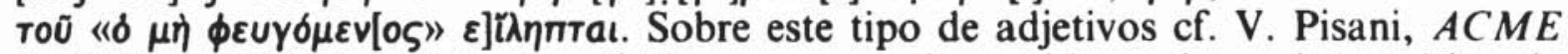
1,1948 , p. 263. A la lista de adjetivos en - $\sigma$ los de sentido pasivo o intransitivo de

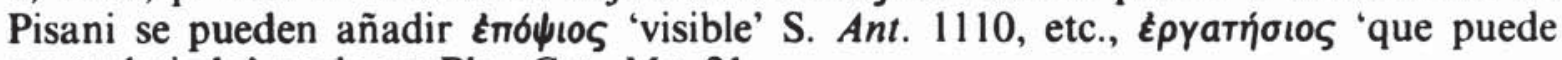
ser trabajado' prob. en Plu. Cat. Ma. 21.

24 M. Treu, Alkaios Lieder, Munich $1963_{3}$, p. 74.

${ }^{25}$ Primero en «Nuove letture nei libri Sulla Poesia di Demetrio Lacone», CErc. 8, 1978 , p. 104 ss. La misma edición, acompañada de un más amplio comentario, aparece de forma definitiva en Demetrio Lacone, La Poesia (PHerc. 188 e 1014), ed., 


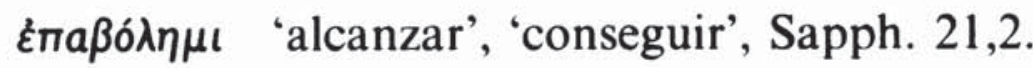

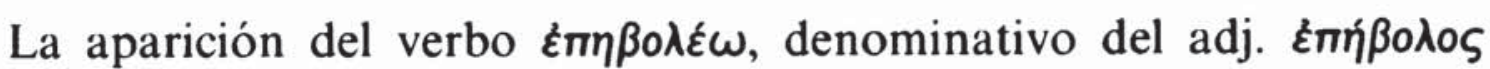
significando 'alcanzar', 'obtener', 'ganar', en dos textos líricos antiguos

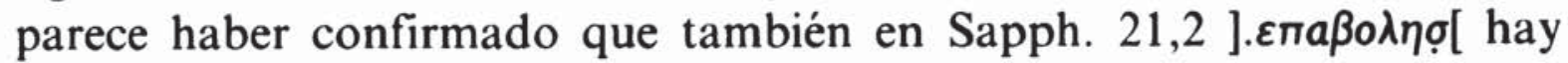
que leer una forma de aoristo del mismo verbo ${ }^{26}$. En el primer testimo-

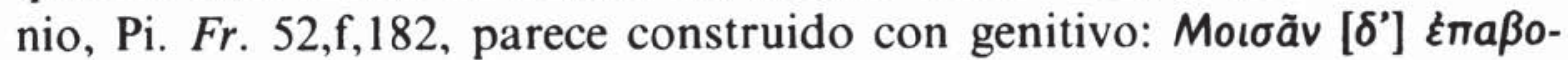

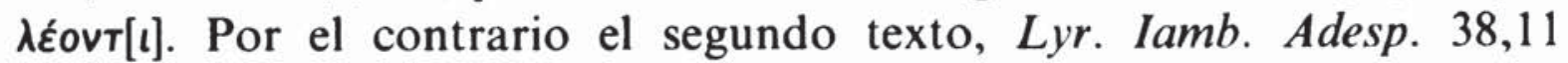
West, presenta acusativo: таũT' $\varepsilon \pi \eta \beta \delta ́ \lambda \eta[\sigma] \varepsilon$. En Safo la construcción no es clara, pues ignoramos si el acusativo ö̀oфuv del verso 3 constituye el objeto directo.

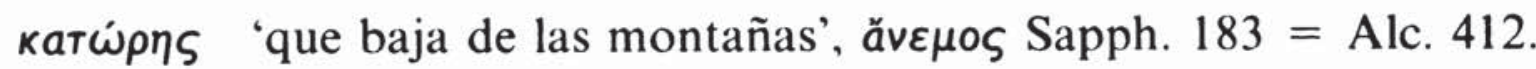

La forma de esta glosa, atribuida tanto a Alceo como a Safo, varía en nuestras fuentes, pues Porfirio, Hesiquio y Teognosto presentan

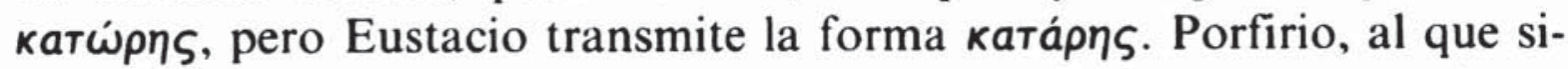

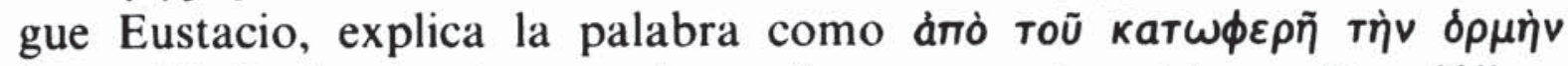

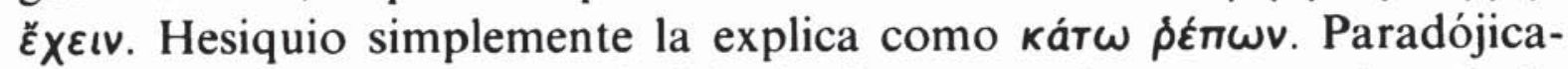

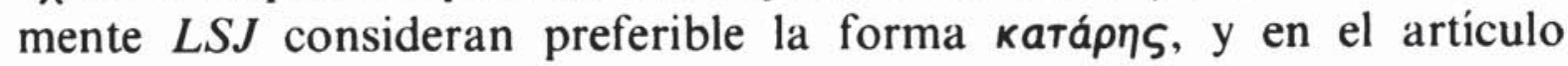

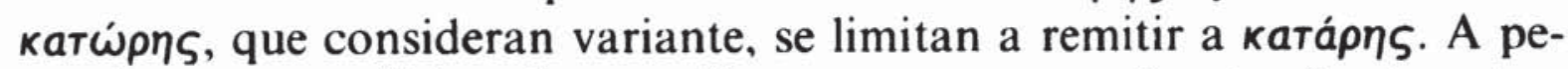
sar de que esta última forma sólo aparece en una fuente, frente a tres

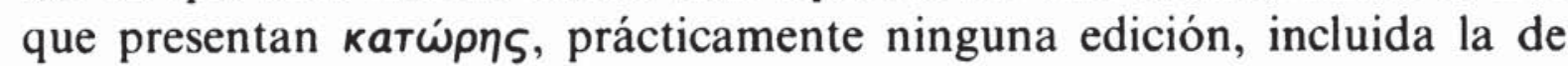
Voigt, se decide por una u otra. Y sin embargo ya $\mathrm{Hamm}^{27}$, a quien si-

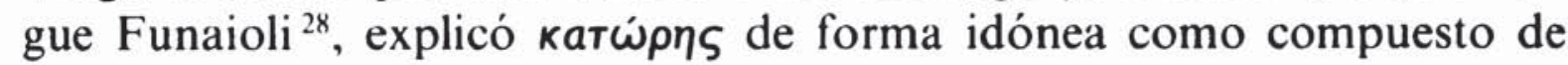
ката̀ y öрos, basándose entre otras razones en el término homérico

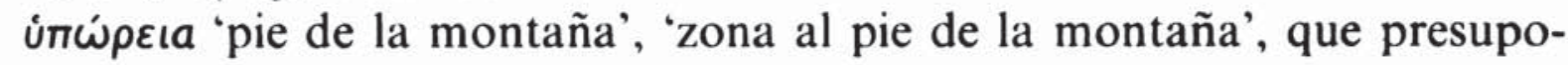
ne la existencia de un adjetivo *u்

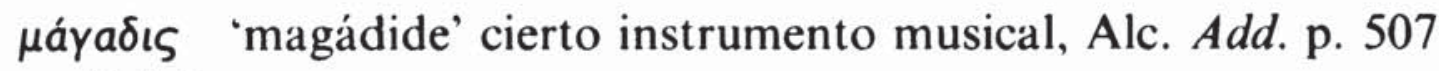
Voigt.

En la última página de la edición de Voigt aparece un addendum alcaico consistente en una glosa de un códice ciriliano conservado en Ma-

trad. y comm. a cura di C. Romeo, La Scuola di Epicuro IX, Nápoles 1988, p. 124, cf. p. 298 ss., donde expone las diversas soluciones propuestas al problema desde Bergk.

${ }_{26}$ Sobre las propuestas anteriores, que querian ver ya una forma del verbo

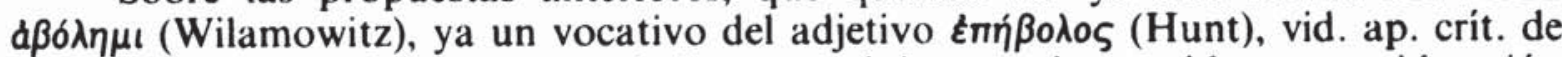
Voigt. Esta última fue la que gozó de mayor éxito, y así es tenida en consideración entre otros por Hamm, op. cit., p. 99, $\S 182 \mathrm{a} .4$ y por $L S J$ s.u. émíßoגos.

${ }_{27}$ E. M. Hamm, Grammatik zu Sappho und Alkaios, Abh. Berlin. 2, 1957, p. 88, $\S 171 b$.

${ }^{28} M C r .8 / 9,1973 / 74$, p. 129 s. 
drid y editado por Naoumides ${ }^{29}$ : фoĩvıł

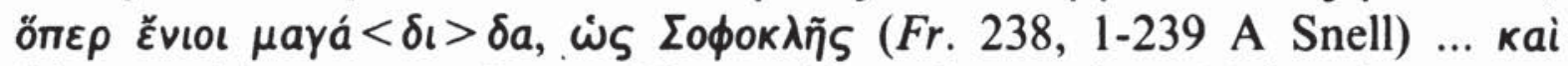

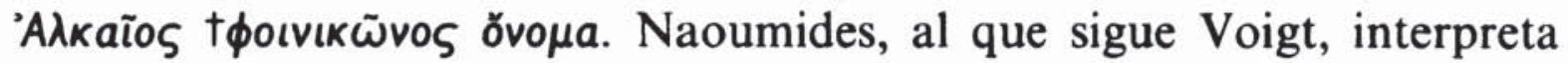
que Alceo utilizó la palabra фoĩvı

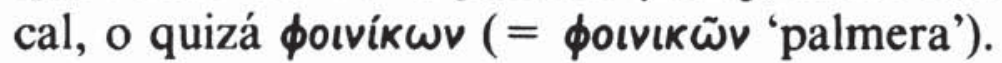

En un trabajo posterior V. Tammaro ${ }^{30}$ interpreta que $\dot{\omega} \varsigma$ seguido de las menciones de Sófocles y Alceo supone una ampliación a öпrp

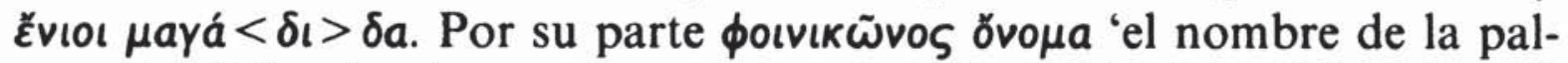
mera', señala simplemente un nuevo significado de la palabra фoĩvı $\zeta$, igual que, explicando otros sentidos de фoĩvı, se ha dicho anteriormen-

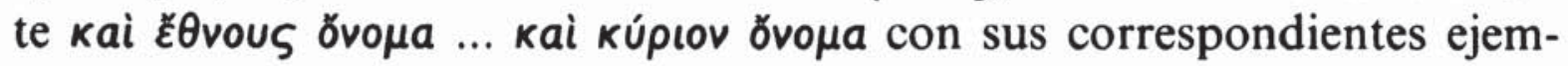

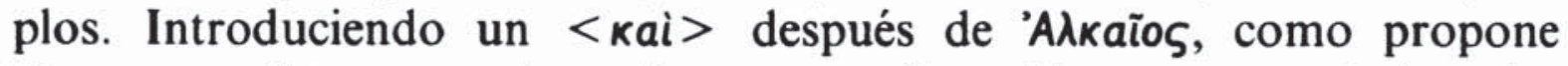
Tammaro, el texto queda perfectamente claro. En consecuencia la pala-

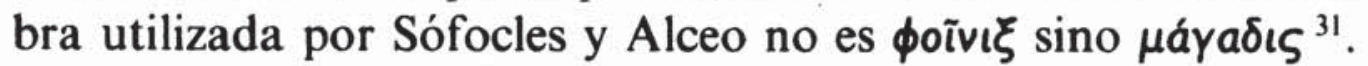

En segundo lugar Tammaro propone que en el códice el nombre ' $A \lambda$ кaĩos procedería de una errónea interpretación de 'A $A \kappa(\mu \tilde{a} v)$, ya que el término está documentado en un fragmento de Alcmán (101 Page). Esto último resulta mucho más dudoso, pues tanto Safo como Alceo, aparte de otras referencias a la actividad musical, nos transmiten los nombres de diversos instrumentos, la mayoría de ellos nuevos y algunos procedentes, como $\mu a ́ \gamma a \delta ı \varsigma$, de préstamo de alguna lengua oriental: $\beta a ́ \rho-$

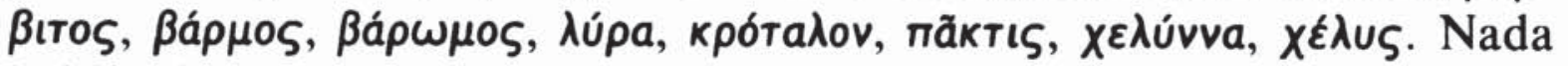

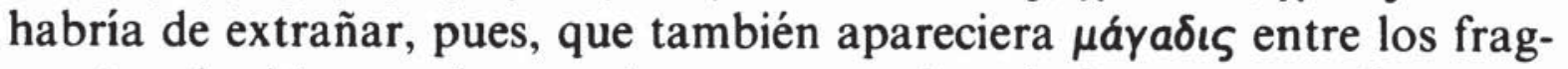
mentos de Alceo, más cuando es un nombre de instrumento frecuente en la lírica antigua. Aparte de Alcmán lo utilizan Anacr. 96,1 y Telest. 4,2, y después está en los trágicos y autores posteriores. Así pues, mientras no haya más pruebas de que en el códice ciriliano el nombre 'Aגkaĩos ha sustituido a una abreviatura, habrá que seguir considerando

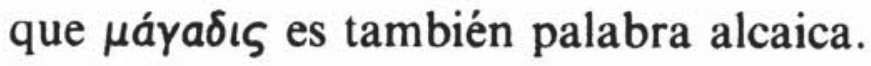

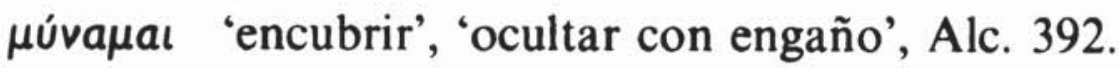

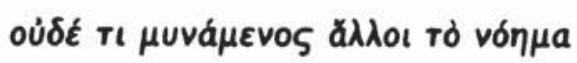

A la luz de la comparación con su exacto paralelo hitita munnai-, expuesta en un trabajo propio de próxima aparición hecho en colabora-

${ }^{29}$ Cyr. cod. Matrit. Bibl. Univ. Z-22 n. ${ }^{\circ}$ 16, editado en GRBS 9, 1968, p. 272.

30 MCr. 8/9, 1973/74, p. 139 s.

${ }^{31}$ M. L. West, «Notes on Sappho and Alcaeus", ZPE 80, 1990, p. 7, todavía ignora el trabajo de Tammaro, cree que la parte que corresponde a Alceo es фoivík $\omega$ -

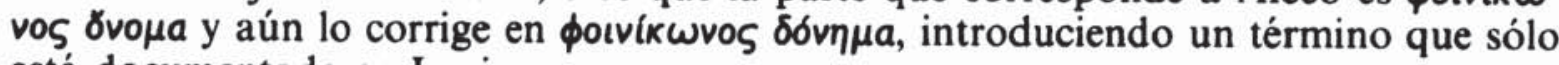
está documentado en Luciano. 
ción con A. Bernabé ${ }^{32}$, se ha revelado que el verdadero significado de este arcaico verbo no es 'desviar' sino 'encubrir', 'ocultar con engaño', en este caso rò vónua 'el propósito', 'las intenciones'. Las interpretaciones confusas de los gramáticos y escoliastas antiguos reflejan un desconocimiento total de la palabra y de su relación con el sustantivo de que deriva, $\mu$ úv $\eta$ 'excusa', 'falso pretexto', documentado en $O d$. XXI 111.

vó $\mu$ เoua 'orden’, 'disciplina’ de un ejército, Alc. 382,2.

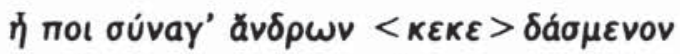

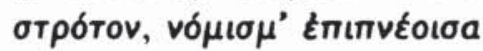

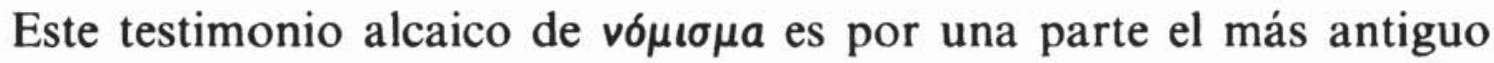
que conocemos, pero además presenta un sentido muy original. El significado primitivo de 'algo consagrado por el uso normal o establecido', que en griego derivó en general hacia los sentidos 'costumbre' y 'moneda', ha pasado aquí a designar la disposición acostumbrada o correcta de un ejército, y por tanto su 'disciplina' u 'orden' ${ }^{33}$.

$\delta \lambda ı \sigma \beta \delta \delta о к о \varsigma$ 'que recibe un consolador', Alc. $303 \mathrm{Aa}, 5$ Voigt $=$ Sapph. 99 i,5 Lobel-Page.

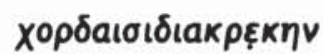

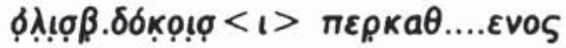

En un fragmento papiráceo de atribución discutida ${ }^{34}$ apareció este compuesto, cuya lectura parece segura, que ha suscitado multitud de discusiones tanto por su significado obsceno como por el hecho de no

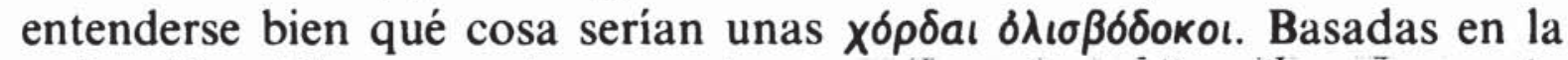
atribución sáfica aparecieron varias tentativas de explicación, alguna de ellas moralizante, que en mi opinión distan mucho de ser satisfactorias $^{35}$. Personalmente considero preferible la atribución a Alceo, pero independientemente de ello creo que la forma más sencilla, literal y al mismo tiempo adecuada de entender el texto es considerar que las cuer-

${ }^{32}$ A. Bernabé-H. Rodriguez Somolinos, «Hitita munnai-, griego $\mu u v a ́ \mu \varepsilon v o \varsigma, \mu u ́ v \eta$, duúvw", que aparecerá próximamente en la revista Glotta.

${ }^{33}$ Cuestión aparte es la consideración de $\varepsilon n ı \pi v \varepsilon o r \sigma a$ como 'inspirando' o como

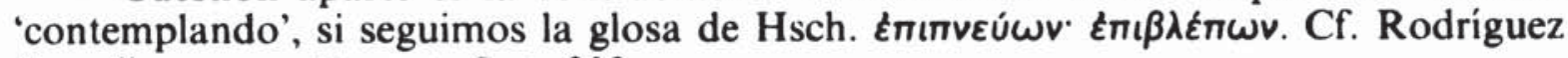
Somolinos, op. cit. en n. 5, p. 209.

${ }^{34}$ El fragmento fue atribuido por Lobel-Page a Safo, pero Voigt considera, siguiendo a varios críticos, que es de Alceo. Cf. A. W. Gomme, "Interpretations of some poems of Alkaios and Sappho", JHS 77, 1957, p. 260 s.

${ }^{35}$ Cf. Rodríguez Somolinos, op. cit. en n. 5, p. 287 s. 


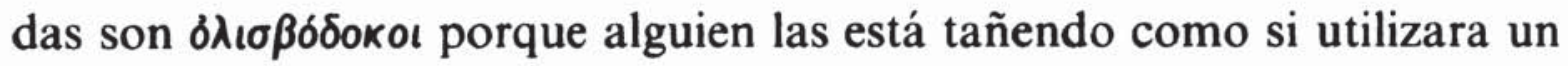

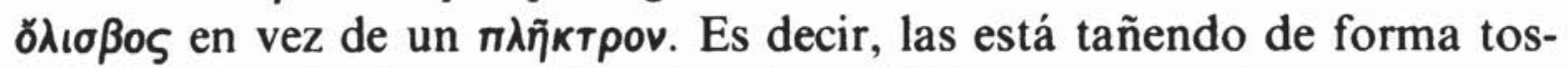
ca, y no con la finura y limpieza de sonido que se obtiene cuando se utiliza correctamente el plectro. El personaje en cuestión puede ser una

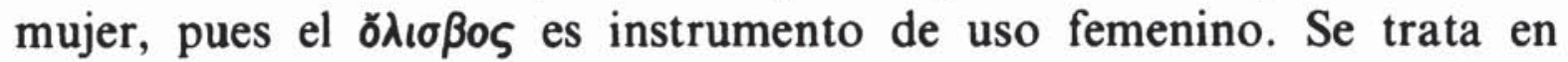
suma de una sarcástica y feroz burla, presumiblemente contra una hetera en el banquete, y no se puede desechar una grosera sugerencia a la mujer de dedicarse a actividades más propias de su sexo o de su oficio, y no intentar hacer lo que no sabe.

En este contexto resulta sugerente el corte propuesto por Lobel y

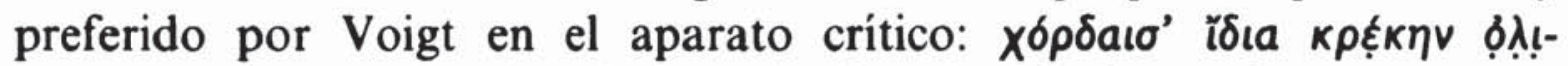

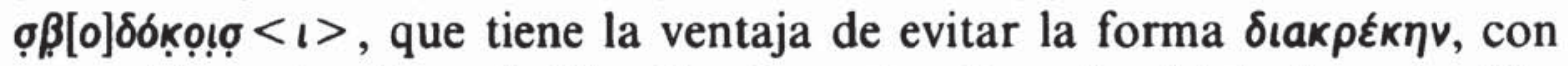
preverbio anómalo en lesbio. Usado en función adverbial, el neutro í $₫ a$ significaría 'de forma peculiar o excéntrica', sentido documentado para

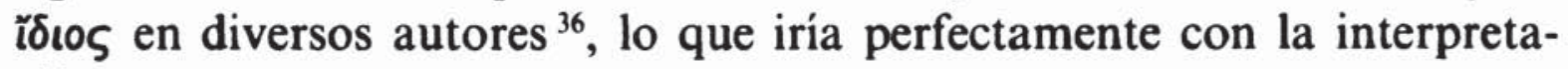
ción que proponemos.

$\pi \varepsilon \delta a \delta \varepsilon v ́ o \mu a \iota$ 'arrepentirse', Alc. 358,6.

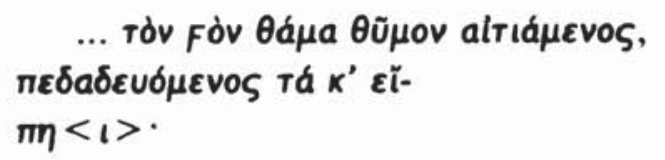

Las principales ediciones, Voigt incluida, presentan la forma $\pi \varepsilon \delta a \lambda \varepsilon u-$

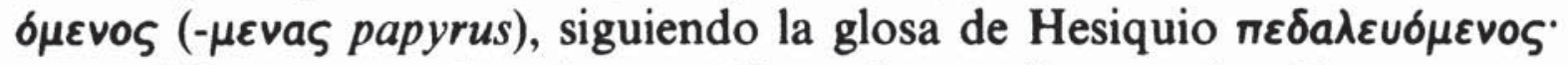

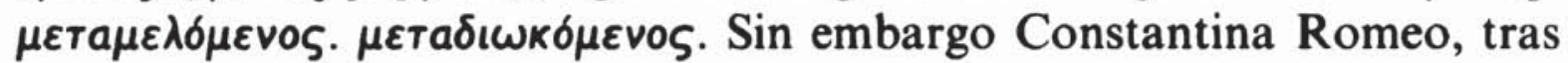

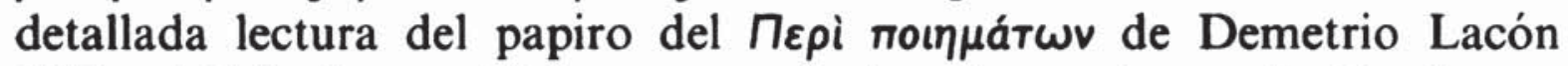
(PErc. 1014), fuente del fragmento alcaico, llega a la conclusión de que lo que hay que leer es $\pi \varepsilon \delta a \delta \varepsilon v \delta \mu_{\varepsilon v}{ }{ }^{37}$. Dos llamativas glosas de Hesi-

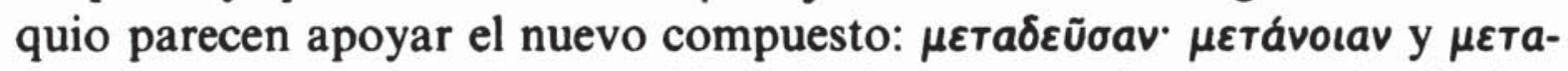

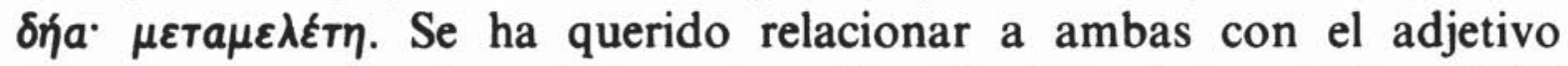

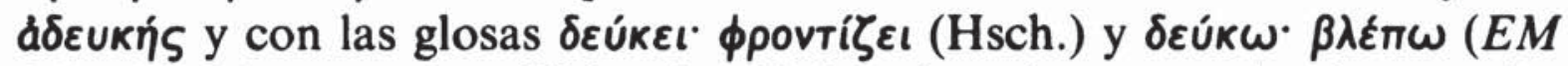
260,54 G.), pero el análisis etimológico de todos estos términos, $\pi \varepsilon \delta a-$ $\delta \varepsilon \cup \delta \mu_{\varepsilon v}{ }^{\prime}$ incluido, dista mucho de estar claro ${ }^{38}$.

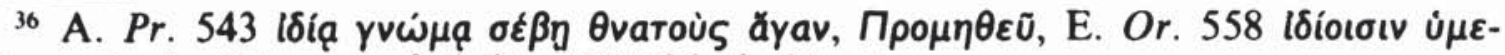

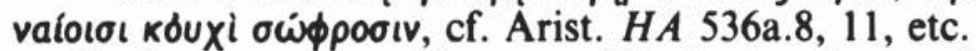

${ }^{37}$ C. Romeo, op. cit. en n. 23. Según el ap. crít. de Romeo esta lectura había sido ya sospechada por Schmidt; R. Philippson, ante la evidencia de que la segunda delta no se leía bien, propuso $\pi \varepsilon \delta a v \varepsilon v \delta ́ \mu \varepsilon v o \zeta ~ e n ~ P h W . ~ 44,1924$, p. 313 ss.

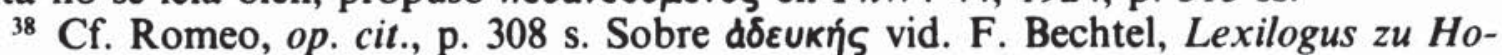
mer, Halle 1914, p. 12, y DGE I s.u.; K. Latte, Hesychios Lexicon, Copenhague

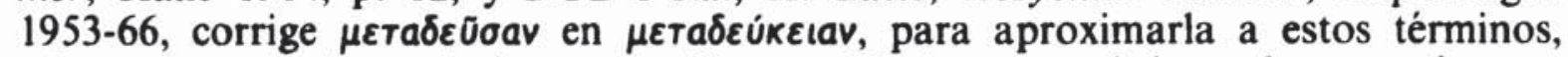
mientras que sugiere relacionar $\mu \varepsilon т a \delta \dot{\eta} a$ con $\delta \dot{\eta} \omega$ 'encontrar', lo cual es muy inverosímil. En cualquier caso ambas glosas parecen estar relacionadas. 
прштаגia 'primera navegación', Alc. 43,4.

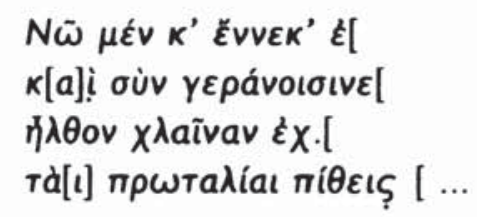

La edición de Voigt considera, junto a otros autores ${ }^{39}$, que en la se-

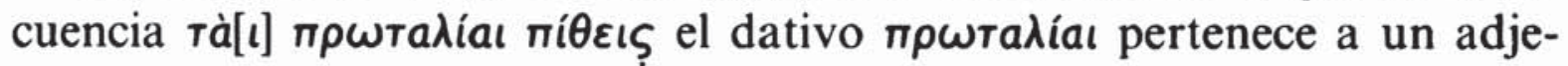
tivo femenino sustantivado con el significado de '(nave) que realiza su

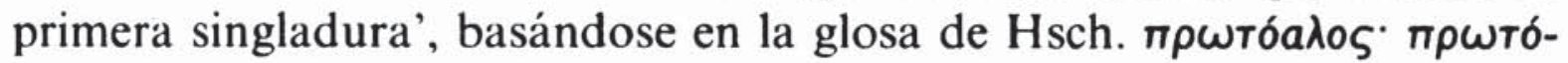
$\pi \lambda o o s$, en la comparación con ( $v \tilde{\eta} a) \pi \rho \omega т o ́ \pi \lambda o o v$ en $O d$. VIII 35 y en la

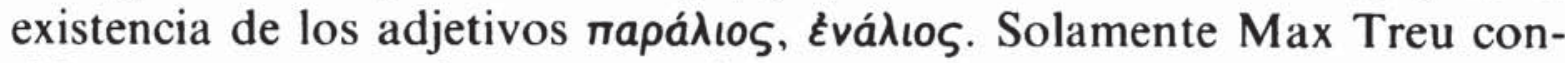
sidera que se trata de un sustantivo con el significado de 'primera navegación', es decir, la primera navegación de la temporada, una vez que ha pasado la estación invernal en que es imposible echarse a la $\operatorname{mar}^{40}$. Nada hay que objetar a esta interpretación, ya que se trata en tal caso de un derivado abstracto regular en -íá, a partir de un adjetivo temático

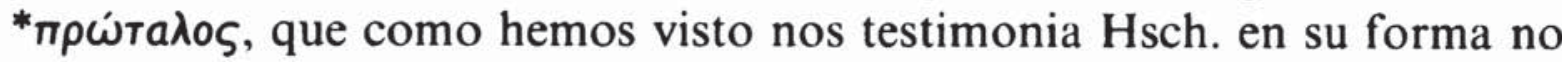
contracta. Este tipo de formación de abstractos, que suelen corresponder a ático -ıă $<-y a ̆$, es bastante frecuente en el léxico de Safo y Alceo, que nos testimonian por primera vez varios de ellos ${ }^{41}$. Precisamente si se tratase de un adjetivo esperariamos la forma *

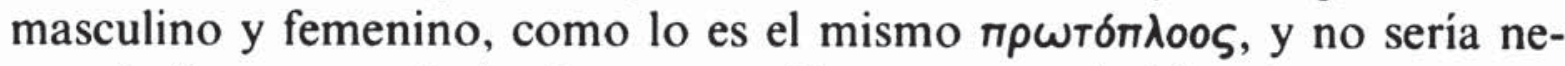

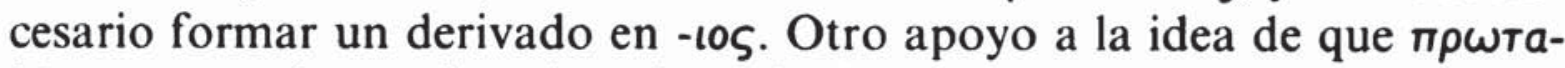

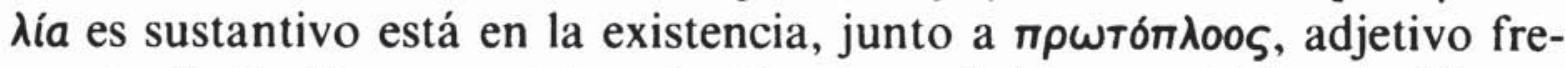

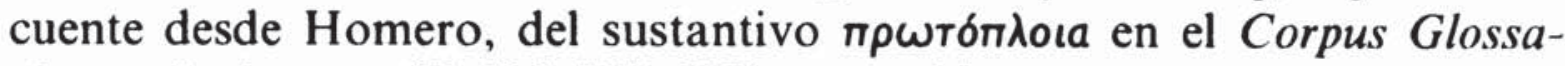
riorum Latinorum (II 425, VII 630), traducido como primum nauigium.

Por otro lado Treu consideraba, siguiendo a Hunt, editor del papi-

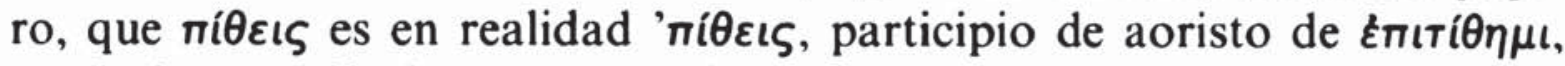
es decir, 'poniéndome', 'colocándome' la x xaĩva mencionada ${ }^{42}$. Ya Hamm sugirió que en realidad se trata del participio presente de $\pi i \theta \eta \mu$,

${ }^{39} \mathrm{Ya}$ antes en Hamm, op. cit., p. $102, \S 185$, cf. C. Gallavotti, Storia e poesia di Lesbo nel VII-VI secolo a.C.: Alceo di Mitilene, Bari 1948, p. 98.

${ }^{40}$ M. Treu, Alkaios Lieder, Munich $1963_{3}$, p. 161 s.; W. Barner, Neue AlkaiosPapyri aus Oxyrrhinchus, Spudasmata XIV, Tubinga-Hildesheim 1967, p. 15 y n. 1 parece darle la razón.

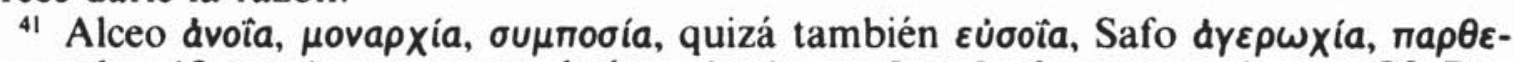

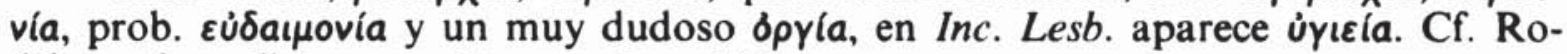
dríguez Somolinos, op. cit. en n. 5, p. 144.

${ }_{42}$ Op. cit., p. 59 «wir beide (?) wegen ... und mit den Kranichen ... kam ich, angetan mit einem Mantel ... der ich übergeworfen hatte (als Schutze) bei der Seefahrt in den frühen Jahreszeit". 
idea generalmente aceptada ${ }^{43}$. Esta última interpretación refuerza aún

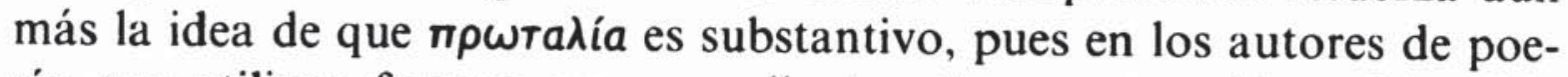
sía que utilizan formas correspondientes al presente $\pi \bullet \hat{\varepsilon} \omega$, el sentido más frecuente, aun tratándose de la voz activa, es el de 'confiar en', 'tener confianza en', 'poner las esperanzas en' con régimen en dativo:

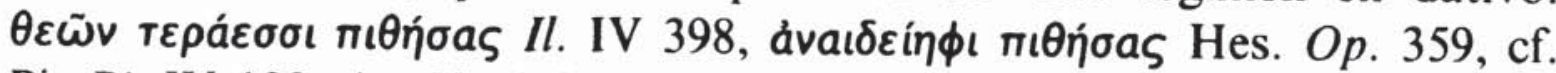
Pi. Pi. IV 109, A. Ch. 618, Lyc. 735 y especialmente Hes. Op. 671 ávé-

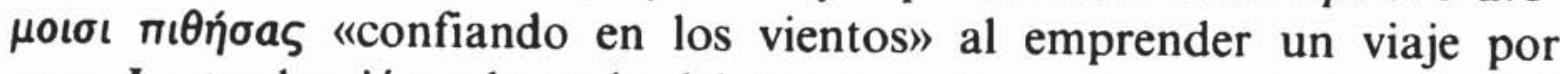
mar. La traducción adecuada del verso alcaico sería por tanto «confiado en la primera navegación de la estación».

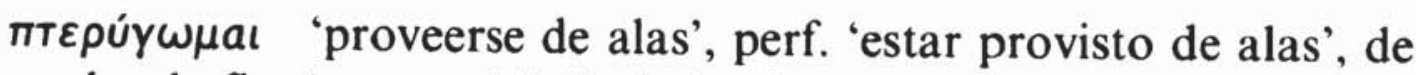
donde fig. 'estar cobijado bajo alas', 'protegerse entre las alas' de la madre, Inc. Lesb. 25.

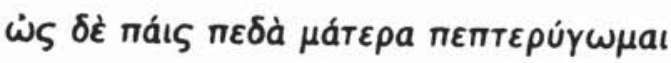

En un trabajo reciente ${ }^{44}$, donde sugiero situar este fragmento entre los epitalamios de Safo, creo haber demostrado con diversos argumen-

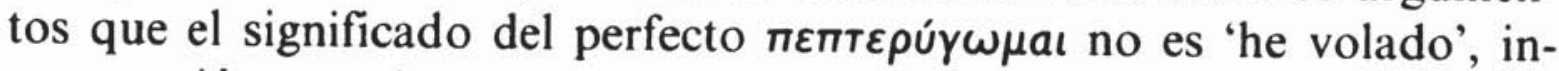
terpretación para la que fallan el tiempo verbal, la preposición y la falta de paralelos, sino 'estoy cobijado bajo las alas', y en sentido amplio o figurado 'me he refugiado', 'estoy cobijado' ${ }^{45}$. En esta idea creo acerta-

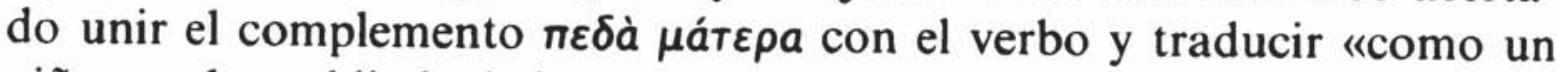
niño me he cobijado bajo las alas de mi madre», en lo que supone la primera aparición en la literatura griega de una imagen común, la del niño cobijándose como los polluelos bajo las alas de su madre.

TúфWs ‘obcecación', 'locura’, Alc. 336.

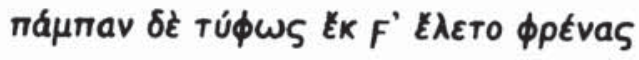

Las ediciones anteriores a Voigt, incluida la de Lobel-Page, aceptaban en general la conjetura de Porson $\delta$ ' $\varepsilon$ rú $\phi \omega \sigma$ ', lo que llevó a $L S J$ a incluir esta cita en el artículo ruфów. Por el contrario Voigt sigue la lec60,8

${ }^{43}$ Op. cit., p. 140, § 227b. El verbo se documenta también en Alc. 17b,28, Sapph.

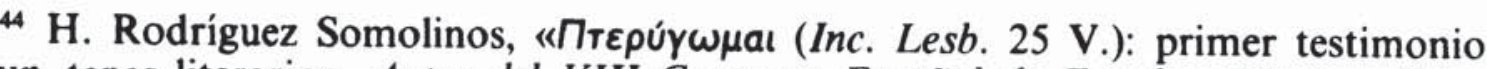
de un topos literario", Actas del VIII Congreso Español de Estudios Clásicos (Madrid, septiembre 1991), vol. II, Madrid 1994, p. 377 ss.

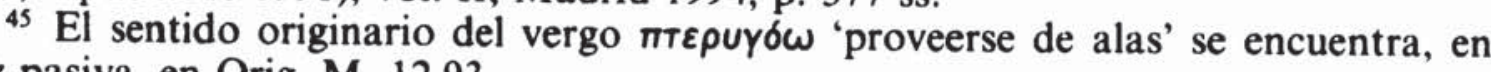
voz pasiva, en Orig. M. 12,93. 
tura de Schneidewin, más cercana al texto ofrecido por las fuentes, y edita el fragmento tal y como queda expuesto. Siguiendo esta interpretación nos encontramos con un substantivo rú $\phi \omega \varsigma$ que presenta el sen-

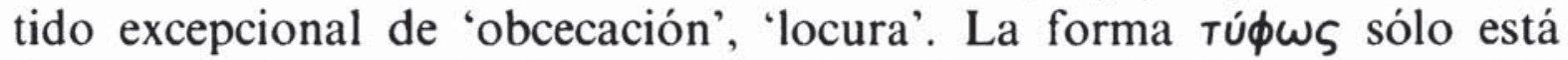
documentada antes de Alceo como el nombre propio del monstruo Tifón o Tifeo. En algunos textos aislados de comedia y tragedia se utiliza con el sentido propio de 'vendaval', 'tifón'. Sin embargo, para el uso figurado que encontramos en Alceo se utiliza normalmente la forma temática rũ

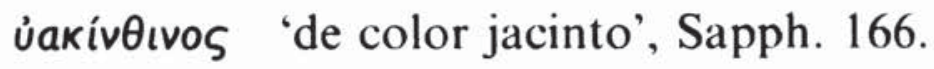

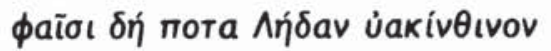

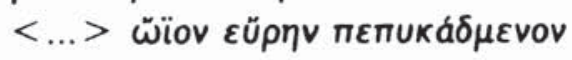

Basándose en la comparación con $O d$. VI 231 = XXIII 158 кópas

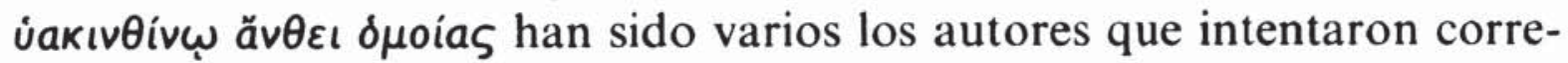
gir este fragmento de Safo introduciendo la palabra ăv $\theta$ os concordando con el adjetivo. Más acertado resulta, como hacen Lobel-Page y Voigt, mantener el texto según ha sido transmitido. En consecuencia el adjetivo ủakívivvos posee aquí por sí solo la noción de color. Se trata del primer testimonio de este empleo, pero además presenta características especiales. El adjetivo v́akívivos está documentado con valor cromático en algún texto epigráfico y en diversos autores literarios, en general muy posteriores a nuestra poetisa ${ }^{46}$. En todos ellos se aplica a prendas de vestir, tejidos o materiales teñidos de ese color ${ }^{47}$. Ello aumenta la originalidad del uso sáfico aplicado a un huevo, pues es dudoso que en su época fuera ya un término técnico procedente de la industria textil, como parece serlo en épocas posteriores. Más bien debe de tratarse de una variación poética con respecto al giro homérico mencionado.

Tras la simple definición 'hyacinthine', el artículo v́axiveıvos de $L S J$, que ignora el testimonio de Safo, se limita a enumerar algunas de estas citas y aquellas en que, como en Homero, tiene un sentido que po-

46 Michel 832,14 (Samos Iv a.C.), más recientemente editada en Ath. Mitt. 68, 1953, p. 46-49, Apoc. 9,17, Pers. I 32, Cod. Iust. IV 40,1 y diversas citas en Josefo, Filón y el Antiguo Testamento. Cf. v̇akıv $\theta$ เvoßaфrís, documentado desde X. Cyr. VI

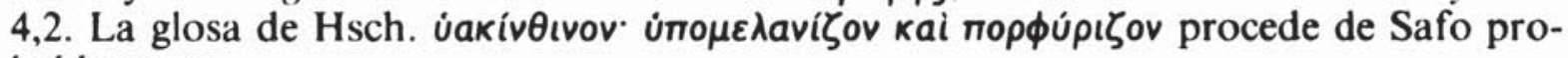
bablemente.

${ }^{47}$ Sobre el tinte de color azul extraido a partir de la planta o plantas denominadas úákıvӨos (y lat. uaccinium) vid. especialmente R. J. Forbes, Studies in Ancient Technology IV, Leiden 1956, p. 113. 


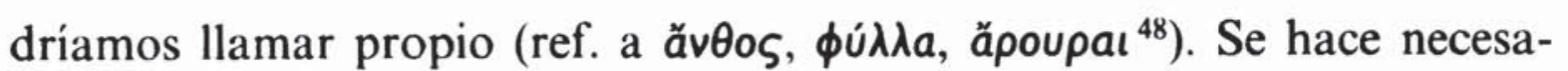
ria la división en dos apartados 1) 'de jacinto' y 2) 'del color del jacinto', este último encabezado por Safo ${ }^{49}$.

$\phi i ̂ \lambda \omega v$ 'amigote', 'camarada', Alc. 70,4.

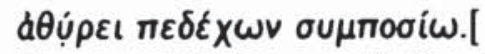

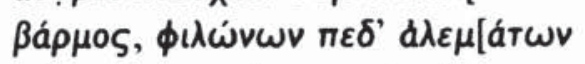 \\ 5

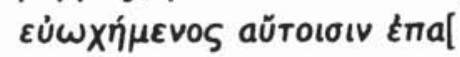

Edgar Lobel, a quien siguen $L S J$, Mastrelli y Page ${ }^{50}$, sugirió que $\phi i ́ \lambda \omega v$ era la misma palabra que Theognost. Can. 12 transmite como

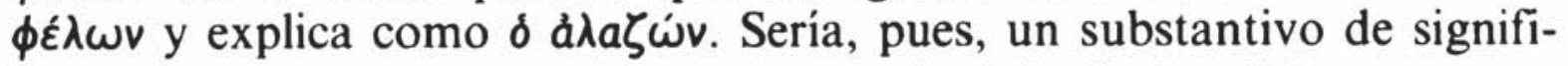
cado 'jactancioso', 'fanfarrón', acompañado del adjetivo á $\lambda \dot{\mu} \mu a t o \varsigma$, cuyo sentido aplicado a personas es 'superficial', 'ocioso' ${ }^{51}$. Esta interpretación supone en primer lugar cierta redundancia en los significados del sustantivo y el adjetivo, pero el principal problema que plantea es el cambio de vocalismo entre $\phi i ́ \lambda \omega v$ y $\phi \varepsilon \hat{\varepsilon} \omega \nu$, prácticamente injustificable. Más adecuado es considerar, como sugirió Maas, aceptaron Theander, Diehl y Hamm, y recoge el diccionario etimológico de Chantraine, que se trata de un derivado popular de $\phi$ í̀os, significando algo así como 'camarada' 'amigote' ${ }^{52}$. A mi modo de ver el principal apoyo de esta idea es que el sufijo - $\omega v$, que forma derivados populares y coloquiales, y entre ellos muchos nombres propios, se muestra especialmente activo en la lengua de Alceo, como demuestran los términos yáotpwv (Alc. 429,5 ) у фú $\sigma \omega \omega v$ (Alc. 129,21, 429,4) ${ }^{53}$. La propia forma $\Phi i ́ \lambda \omega v$ constituye un antropónimo común en griego.

Como se ha podido comprobar algunas de las interpretaciones o lecturas expuestas son prácticamente seguras, mientras que otras aún permanecen en el terreno de la hipótesis. Creo que tanto unas como otras

48 A las que habría que añadir v́akıv $\theta i v \eta$ paßjos en Anacreont. 31,1 Preisendanz, West, Brioso $=7$ Michelangeli.

49 Sobre la identificación del color vid. Rodríguez Somolinos, op. cit., p. 225 y nn. 336 y 337, la bibliografia alli mencionada y Forbes, loc. cit.

so C. Mastrelli, La Lingua di Alceo, Florencia 1954, p. 74; Page, op. cit., p. 235 s.

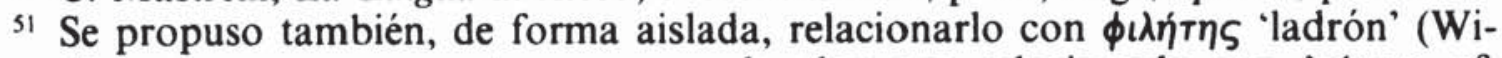

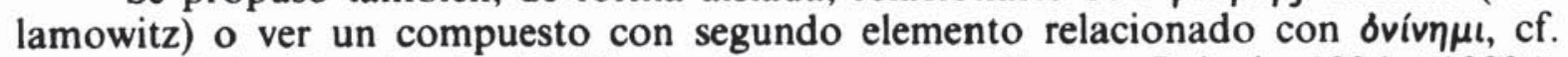

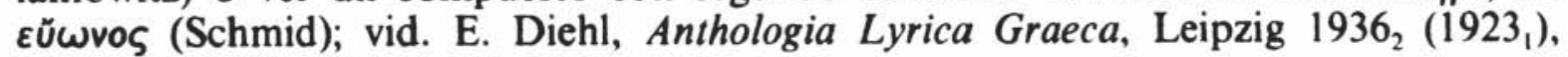
vol. I 4, fr. 43, p. 106.

s2 P. Maas, "Ein neuer Alkäischer Zweizeiler», WKPh. 32, 1915, p. 598, C.

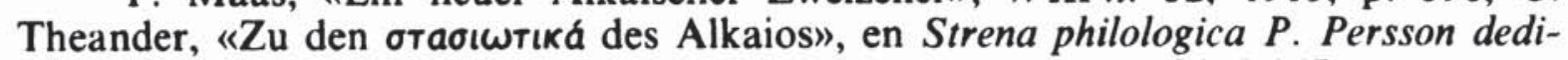
cata, Upsala 1922, p. 57 ss., Diehl, loc. cit., Hamm, op. cit., p. 84, § 167c.

${ }_{53}$ Quizá también oxúpwv en Alc. 167,3, cf. 174,2, 58,13. Sobre el sufijo cf. P. Chantraine, La formation des noms en grec ancien, París 1933, p. 160 s. 
serán de utilidad para la lexicografia, y en casos particulares podrán ayudar a la comprensión de pasajes discutidos, cuando no simplemente desatendidos. Confiando en dicha utilidad espero que esta serie pueda verse continuada en un futuro.

Helena Rodríguez Somolinos 